\title{
Predicting Facebook addiction and state anxiety without Facebook by gender, trait anxiety, Facebook intensity, and different Facebook activities
}

\author{
WENJING $\mathrm{XIE}^{1 *}$ and KAVITA KARAN ${ }^{2}$ \\ ${ }^{1}$ School of Communication and the Arts, Marist College, Poughkeepsie, NY, USA \\ ${ }^{2}$ School of Journalism, Southern Illinois University Carbondale, Carbondale, IL, USA
}

(Received: July 20, 2018; revised manuscript received: November 15, 2018; accepted: February 19, 2019)

\begin{abstract}
Background and aims: Although social networking sites brought giant convenience, many negative effects on users' psychological well-being need more investigation. This study used a survey to examine Facebook addiction and state anxiety without Facebook. As research shows gender is related to trait anxiety and may interact with trait anxiety to influence state anxiety, we also assess the interaction effect between gender and trait anxiety. Methods: A total of 526 college students in the US participated in the survey. A systematic sampling method was used and an e-mail invitation with the link of the survey was sent to every third student on the students' e-mail list. Study measures included demographics, trait anxiety, Facebook intensity, different Facebook activities, Facebook addiction, and state anxiety without Facebook. Hierarchical multiple regression was run to test how trait anxiety, gender, Facebook intensity, and different types of Facebook activities predict Facebook addiction and state anxiety. Results: Facebook use intensity predicts Facebook addiction $(\beta=0.573, p<.001)$ and state anxiety $(\beta=0.567, p<.001)$. Facebook use for broadcasting positively predicts Facebook addiction $(\beta=0.200, p<.01)$ and state anxiety $(\beta=0.171, p<.01)$. Trait anxiety positively predicts Facebook addiction $(\beta=0.121, p<.05)$ and state anxiety $(\beta=0.119, p<.05)$. Gender interacts with trait anxiety and jointly predicts Facebook addiction $(\beta=0.201, p<.01)$. Discussion and conclusions: Trait anxiety, Facebook intensity, and broadcasting behavior on Facebook positively predict Facebook addiction and state anxiety. Moreover, gender interacts with trait anxiety, so that the gender difference in Facebook addiction is significant only when trait anxiety is low.
\end{abstract}

Keywords: Facebook, social media, problematic Facebook use, addiction, anxiety

\section{INTRODUCTION}

Social networking sites (SNSs) are becoming increasingly influential. Statistics show that $68 \%$ of the US adults are Facebook users (Smith \& Anderson, 2018) and over 70\% of Facebook users log in every day (Chaffey, 2017). Moreover, more than 350 million people around the world are believed to meet the clinical definition of an addiction because of their Facebook habits (Gaille, 2017). Studies revealed that Facebook addiction could activate same brain areas as drugs (Castillo, 2015). Thus, it is essential to understand the underlying mechanism behind Facebook addiction (Andreassen \& Pallesen, 2014; Przepiorka \& Blachnio, 2016). This study used a survey to examine how gender, trait anxiety, Facebook use intensity, and different types of uses contribute to Facebook addiction and state anxiety without Facebook.

\section{SNS addiction}

Addiction refers to "repeated failures to refrain from drug use despite prior resolutions to do so" (West \& Brown, 2013, p. 7). Recently, addiction to SNSs attracts scholars' attention. SNS addiction was defined as being overly concerned about SNSs or driven by a strong motivation to $\log$ onto SNSs, so that it impairs normal social activities and/or psychological health and well-being (Andreassen \& Pallesen, 2014). Behavioral patterns of obsessively checking SNS have been studied in relation to usage patterns, motivations, and negative consequences (Andreassen et al., 2013; Andreassen, Torsheim, Brunborg, \& Pallesen, 2012). These studies maintain that not only the overuse of SNSs may lead to SNS addiction (Andreassen et al., 2013), but also young generation's addiction to social media may be suffering from intrapsychic conflict.

Regarding the heavy use of SNSs, scholars have expressed their concerns with virtual spaces' impacts on actual health issues (O'Keeffe \& Clarke-Pearson, 2011). Studies show that SNSs are likely to engender negative consequences on mental health, including anxiety, insomnia, and decrease in real-life communities (Kuss \& Griffiths, 2011; Pantic, 2014). "Facebook depression" is one of such mental health issues. As a symptom which happens when

* Corresponding author: Assoc. Prof. Wenjing Xie; School of Communication and the Arts, Marist College, 3399 North Road, Poughkeepsie, NY 12601, USA; Phone: +1 845575 3000; Fax: +1 845575 3885; E-mail: wenjing.xie@marist.edu

This is an open-access article distributed under the terms of the Creative Commons Attribution-NonCommercial 4.0 International License, which permits unrestricted use, distribution, and reproduction in any medium for non-commercial purposes, provided the original author and source are credited, a link to the CC License is provided, and changes - if any - are indicated. 
users spend a substantial and excessive amount of time on Facebook, Facebook depression begins to exhibit classic symptoms of depression (O'Keeffe \& Clarke-Pearson, 2011).

Studies demonstrate that SNS addiction needs to be scrutinized with different approaches (Kuss, Griffiths, Karila, \& Billieux, 2014). Research shows that determinants of Facebook addiction include gender (Andreassen et al., 2013; Turel, He, Xue, Xiao, \& Bechara, 2014), time spent on the Internet (Hormes, Kearns, \& Timko, 2014; Marino, Gini, Vieno, \& Spada, 2018a, 2018b), motivations such as relationship maintenance, entertainment, and companionship (Ryan, Chester, Reece, \& Xenos, 2014), and personalities such as neuroticism and consciousness (Andreassen et al., 2012). However, Marino et al.'s (2018a, 2018b) metaanalysis on Facebook addiction suggested that future research should examine frequency of different Facebook activities and other personality factors.

\section{Anxiety}

Anxiety was defined as a negative emotion characterized by an unpleasant state of inner turmoil, often accompanied by nervous behavior (Seligman, Walker, \& Rosenhan, 2001; Spielberger, 1972). In contrast with fear, which is induced by real or immediate threat, anxiety is an unpleasant feeling or expectation of future threat (American Psychiatric Association, 2013). Anxiety may be induced when there is a lack of enough information to make appropriate judgments or decisions about the changing environment (Xie \& Newhagen, 2014).

Spielberger (1972) distinguished trait anxiety from state anxiety. Trait anxiety is a personality that runs in one's genes and has been considered as a permanent psychological characteristic (Spielberger, 1966). It refers to the stable tendency to attend to and experience negative emotions including worries and fear across various situations (Gidron, 2013). However, state anxiety means how anxious people feel at a moment (Lazarus, 1991). Psychological studies demonstrated that trait anxiety is a strong indicator of state anxiety (Li \& Lopez, 2005). Xie and Newhagen's (2014) research showed that subjects' trait anxiety predicts state anxiety induced by mobile phone.

H1: People with higher level of trait anxiety will report higher level of state anxiety without Facebook.

As an aversive response to stress, anxiety has been linked to addiction. Scholars found that people with higher level of trait anxiety are more likely to develop addictions to substances (Litt, Cooney, \& Morse, 2000). Kushner, Krueger, Frye, and Peterson's (2008) quasi-experiment revealed the co-occurrence between anxiety disorders and substance use disorders. Lai, Cleary, Sitharthan, and Hunt (2015) revealed strong correlations between anxiety and alcohol and drug use. Mehroof and Griffiths' (2010) study showed that trait anxiety has a positive relationship with online gaming addiction. In the realm of SNS, research has revealed the association between problematic Facebook use and signs of psychological distress including anxiety and depression (Koc \& Gulyagci, 2013; Marino et al., 2018b; PrizantPassal, Shechner, \& Aderka, 2016). The reason is people with high psychological vulnerability are more likely to rely on SNS to fulfill their social needs or to regulate their mood online (Hong, Huang, Lin, \& Chiu, 2014; Satici, Saricali, Statici, \& Capan, 2014). However, most of the research focuses on social anxiety (Prizant-Passal et al., 2016; Statici et al., 2014), not trait anxiety.

H2: People with higher level of trait anxiety will report higher level of Facebook addiction.

It is also possible that people who are more addicted to Facebook will experience higher level of state anxiety without Facebook due to dependence on the technologies. Park and Choi (2015) found that compared with people in the low addiction or normal group, those with higher smartphone addiction reported higher level of state anxiety when their phone was taken away. Hawi and Samaha's (2017) survey revealed that people with smartphone addiction demonstrated greater odds of having high state anxiety compared to those who were not addicted.

H3: People with higher level of Facebook addiction will report higher level of state anxiety without Facebook.

\section{Gender and SNS addiction}

Gender has been found to be related to addiction to new technologies (Ikeda \& Nakamura, 2014). However, there has been no consensus regarding the relationship between gender and SNS addiction. While some research show a positive correlation between male users and addiction to games on social media (Smahel, Blinka, \& Ledabyl, 2008), scholars also found that females present more addictive symptoms in Facebook use (Marino et al., 2018a; Thompson \& Lougheed, 2012; Turel et al., 2014). Other scholars, nonetheless, found such gender difference in Facebook addiction small or even null (Beyens, Frison, \& Eggermont, 2016; Koc \& Gulyagci, 2013). Marino et al.'s (2018a) recent meta-analysis of 56 studies revealed a small, higher problematic Facebook use in female. Given such inconsistent findings, scholars suggest that further research is needed to examine gender differences in SNS addiction (Griffiths, 2010).

H4: Female will demonstrate higher level of (a) Facebook addiction and (b) state anxiety.

Moreover, Koc and Gulyaci (2013) suggested that the inconsistent findings about gender differences in SNS addiction warrant further research to examine if gender interacts with other variables in affecting SNS addiction. In fact, research has revealed the interaction effect between gender and personalities on SNS use. For instance, Simoncic, Kuhlman, Vargas, Houchins, and Lopez-Duran's (2014) study detected a three-way interaction effect between gender, neuroticism, and Facebook activity on depressive symptoms. Barker (2009) also found the interaction between gender and self-esteem predicts different SNS activities.

Research shows that females are more likely to develop anxiety disorders than males in both adolescents (Lewinsohn, Gotlib, Lewinsohn, Seeley, \& Allen, 1998) and adults (Donner \& Lowry, 2013) due to genetic factors, physiological reactivity, hormonal influences, and evolution influences (McLean \& Anderson, 2009). Hishinuma, 
Miyamoto, Nishimura, and Nahulu (2000) found that female had higher level of trait anxiety than male. Moreover, gender interacted with trait anxiety in predicting state anxiety. Given the connection between gender and trait anxiety, we have the following question:

$R Q 1$ : Will gender interact with trait anxiety to predict Facebook addiction and state anxiety without Facebook?

\section{Social media use and Facebook addiction}

Research has identified the positive correlation between frequent Facebook use and Facebook addiction (Karaiskos, Tzavellas, Balta, \& Paparrigopoulos, 2010). Thompson and Lougheed (2012) found people who spend more minutes on Facebook are more inclined to feel addicted to the site. Hong et al.'s (2014) study revealed that the amount of time spent on Facebook positively predicts Facebook addictive tendency. Using objective measures, Marino, Finos, Vieno, Lenzi, and Spada (2017) found Facebook addiction is related to frequency of Facebook activities.

H5: Facebook use intensity will be positively related to (a) Facebook addiction and (b) state anxiety.

\section{Different types of Facebook activities}

The uses and gratifications theory (Elihu, Blumler, \& Gurevitch, 1974) suggests that people may use media platforms in different ways for different motivations. As SNSs provide multiple functions, scholars also start to explore the different psychological and behavioral aspects of different types of SNS activities (Marino et al., 2018b). Burke, Kraut, and Marlow (2011) distinguished three types of activities on SNSs. The first one is directed communication with individual friends, including personal, one-on-one exchanges such as sending messages, posting comments on friends' walls or photos, tagging, "liking," and synchronous chat. The second type of SNS activities is passive consumption of social news, which happens when one reads others' updates. The third type of SNS activity is broadcasting, including status updating, sharing pictures or videos, and writing notes. Broadcasting usually is not targeted at a particular person. Instead, it happens when one writes or posts on SNS for general SNS users to read (Burke \& Kraut, 2016).

Scholars have suggested that beyond the frequency and time spent on Facebook, analysis of the relationship between different types of Facebook activities and Facebook addiction is needed (Marino et al., 2018a; Ryan et al., 2014; Ryan, Reece, Chester, \& Xenos, 2016). Ryan et al. (2014) found the use of Facebook for social interaction, passing time, entertainment, companionship, and escape may be related to the development of Facebook addiction. Dhaha (2013) found that social interaction and entertainment are two strongest predictors of Facebook addiction. However, neither of these studies touches on the specific activities on SNSs. Griffiths (2010) found that playing games on SNS is positively linked to SNS addiction. Marino et al. (2017) found problematic Facebook users and non-problematic users differ in several objective behaviors, including the number of events attended, the number of friend requests sent, status update, "like," and shared posts. Ryan et al. (2016) distinguished low engagement users from high engagement users in browsing, social activities, and gaming. As SNS is growing fast and more and more features are available for the users, it is essential to understand how different activities on SNS are related to SNS addiction.

$R Q 2:$ How will different types of SNS activities predict Facebook addiction and state anxiety without Facebook?

\section{METHODS}

\section{Participants}

A survey with 526 students enrolled in a large Midwestern university in the US was conducted in fall 2015. The college students were chosen for several reasons. Statistics show that people between 18 and 29 years old are the largest group among social media users (Greenwood, Perrin, \& Duggan, 2016). Moreover, university students are more vulnerable to Internet addiction because of their flexible schedule and academic pressure (Kandell, 1998). Research also documented college students' addiction to social media (McCrary, 2016).

To ensure the representativeness of the sample, the complete e-mail list of all enrolled students was obtained from the university under the university's Freedom of Information Act Policy. Using a systematic sampling method, an e-mail invitation with the link of the survey was sent to 6,000 students, accounting for one third of the student population. To increase the response rate, two reminder e-mails were sent to the respondents 1 and 2 weeks after the initial invitation. Finally, 526 students completed the survey. The average age of the sample was $24.21(S D=5.92)$. Females accounted for $59 \%$ of the sample and $41 \%$ were male. The majority of the sample was White $(68.4 \%)$, followed by Asian (12.7\%), Hispanic (7.0\%), and Black and African Americans (6.3\%).

\section{Measures}

Facebook intensity. It was measured using Facebook Intensity Scale (Ellison, Steinfield, \& Lampe, 2007), which includes six closed-ended questions such as "Facebook is part of my everyday activity" on a 5-point Likert scale [ranging from 1 (strongly disagree) to 5 (strongly agree)]. There are two more open-ended questions measuring number of Facebook friends and time spent on Facebook. Answers to these questions were evenly divided into five categories. All scores were standardized, and a Facebook use intensity score was created by calculating the mean of the eight items $(M=2.85, S D=1.04$, Cronbach's $\alpha=.83)$.

Facebook addiction. It was measured using Bergen Facebook Addiction Scale (BFAS; Andreassen et al., 2012; Brailovskaia \& Margraf, 2017). The BFAS has six items such as "You feel an urge to use Facebook more and more" measured on a 5-point Likert scale [ranging from 1 (very rarely) to 5 (very often)]. Answers were averaged $(M=3.15, S D=0.71$, Cronbach's $\alpha=.87)$.

Trait anxiety. It was measured using State-Trait Anxiety Inventory (STAI; Spielberger, 2010) - Trait Anxiety, 
ranging from 1 (not at all) to 4 (very much). A new index, trait anxiety, was formed by averaging answers to these 20 questions $(M=2.59, S D=0.62$, Cronbach's $\alpha=.90)$.

State anxiety. To reduce the respondents' fatigue, we used the six-item Short-Form State Anxiety Scale (Marteau \& Bekker, 1992) instead of the original 20-item STAI-State Anxiety (Spielberger, 2010). The Short-Form State Anxiety Scale has been demonstrated to be a highly reliable and valid instrument (Tluczek, Henriques, \& Brown, 2009). The subjects were asked: "If you have lost access to your Facebook account for $48 \mathrm{hr}$, how would you feel right now, at this moment?" Question items include: "I feel tense now," etc., measured on a 4-point Likert scale [ranging from 1 (not at all) to 4 (very much)]. A new index, state anxiety without Facebook, was formed by averaging the item scores $(M=$ 2.01, $S D=0.73$, Cronbach's $\alpha=.83$ ).

Different types of Facebook activities were adopted from previous studies (Burke et al., 2011; Xie \& Kang, 2015; Zhong, 2013), asking the respondents how frequently they use SNS to share pictures, update status, etc., using a 5-point Likert scale [ranging from 1 (not at all) to 5 (very frequently)].

Principal component analysis (PCA) with varimax rotation was performed and generated two factors [PCA is a dimension-reduction technique. We used PCA in this study to condense the information in different types of Facebook activities into a smaller set of new composite variables that represent most of the information in the original set of variables (Dunteman, 1989]. The goal is to reduce the dimensionality of different types of Facebook activities to facilitate data interpretation). Following Burke et al. (2011) and Xie and Kang (2015), the first type of SNS activities was named directed communication, including sending private messages to friends, sending messages to groups, leaving comments on friends' wall or pictures, and liking friends' posts or pictures (Eigenvalue $=3.172$, Cronbach's $\alpha=.89$ ). The second type of SNS activities was named broadcasting, including status update, sharing pictures or videos, and writing notes (Eigenvalue $=1.953$, Cronbach's $\alpha=.91$; Table 1).

Demographics including gender, age, house income, and education were measured.

\section{Procedure}

An online survey was created on the university server. The link of the survey was sent to the participants' e-mail. The participants completed the survey at their convenience.

\section{Statistical analysis}

To test the hypotheses and answer the research questions, two hierarchical linear regression analyses were performed by using IBM SPSS 25.0 (IMB SPSS Inc., Chicago IL, USA). Parameter estimation was performed through ordinary least squares. Facebook addiction and state anxiety without Facebook were entered as the dependent variables, respectively. For both models, demographics were entered in the first block, followed by trait anxiety in the second block. Facebook use intensity was entered in the third block and different types of Facebook use in the fourth block. The interaction term between gender and trait anxiety was entered as the
Table 1. Factor analysis of different types of Facebook use

\begin{tabular}{lcc}
\hline & \multicolumn{2}{c}{ Factor loadings $^{\mathrm{a}}$} \\
\cline { 2 - 3 } & $\begin{array}{c}\text { Directed } \\
\text { communication }\end{array}$ & Broadcasting \\
\hline Variables & 0.848 & \\
\hline Sending private messages & & \\
$\quad$ to friends & 0.844 & \\
Commenting on friends' & & \\
$\quad$ wall, photo, or video & 0.815 & \\
Liking friends' post or & & \\
pictures & 0.810 & 0.814 \\
Sending group instant & & 0.800 \\
$\quad$ messages & & 0.751 \\
Updating status & & 0.689 \\
Sharing pictures & & 27.555 \\
Sharing videos & & 1.953 \\
Writing notes & & .91 \\
Percent variance explained & 44.534 & \\
Eigenvalue & 3.172 & \\
Cronbach's $\alpha$ & .89 & \\
\hline
\end{tabular}

Note. ${ }^{\text {a }}$ Quartimax rotation was employed for the final solution.

last step. To avoid multicollinearity, trait anxiety was centered by subtracting the mean value from the original value. The interaction term between trait anxiety and gender was calculated by multiplying the centered value of trait anxiety with gender.

\section{Ethics}

The participants were provided written informed consent after clicking on the survey link. They had to indicate whether they were willing to participate in the survey and they were above 18 years old to proceed. This study was approved by the institutional review board of Southern Illinois University Carbondale.

\section{RESULTS}

Table 2 shows that trait anxiety was a positive predictor for both Facebook addiction $(\beta=0.121, \quad p<.05, \quad 95 \%$ CI $[0.015,0.037])$ and state anxiety without Facebook $(\beta=0.119, p<.05,95 \%$ CI $[0.002,0.035])$, supporting $H 1$ and $H 2$. Trait anxiety explained $3.2 \%$ of the variances in Facebook addiction $\left(\Delta R^{2}=.032, p<.05\right)$ and $1.3 \%$ of the variances in state anxiety $\left(\Delta R^{2}=.013, p<.05\right)$. People with higher level of Facebook addiction reported higher level of state anxiety without Facebook $(\beta=0.291, p<.001,95 \%$ CI $[0.202,0.338])$, supporting $H 3$.

Gender did not predict either Facebook addiction or state anxiety, and both $H 4 a$ and $H 4 b$ were rejected. However, as shown in Figure 1, the interaction between gender and trait anxiety was a significant predictor of Facebook addiction $(\beta=0.204, p<.01,95 \%$ CI [0.101, 0.203]). Post-hoc analysis shows that among people with lower level of trait anxiety, females had higher level of Facebook addiction $(M=2.53, S D=0.73)$ than males $(M=2.18, S D=0.68)$, $t(282)=2.65, p<.01$. Such gender difference did not exist among those with higher level of trait anxiety. 
Table 2. Hierarchical regression predicting Facebook addiction and state anxiety without Facebook

\begin{tabular}{|c|c|c|c|c|}
\hline & \multicolumn{2}{|c|}{ Facebook addiction } & \multicolumn{2}{|c|}{ State anxiety without Facebook } \\
\hline & $\beta$ & $t$ & $\beta$ & $t$ \\
\hline \multicolumn{5}{|l|}{ Block 1: Demographics } \\
\hline Male & -0.085 & 1.513 & -0.051 & -0.891 \\
\hline Age & 0.020 & 0.314 & 0.015 & 0.237 \\
\hline Education & 0.102 & 1.540 & 0.013 & 0.190 \\
\hline Household income & -0.045 & -0.791 & 0.021 & 0.362 \\
\hline White & -0.083 & -1.612 & -0.092 & -1.569 \\
\hline$\Delta R^{2}$ & .025 & & .011 & \\
\hline \multicolumn{5}{|l|}{ Block 2: Personality } \\
\hline Trait anxiety & 0.121 & $1.926^{*}$ & 0.119 & $1.808^{*}$ \\
\hline$\Delta R^{2}$ & $.032 *$ & & $.013^{*}$ & \\
\hline \multicolumn{5}{|l|}{ Block 3: Facebook use } \\
\hline Facebook use intensity & 0.573 & $12.258^{* * *}$ & 0.567 & $11.869 * * *$ \\
\hline$\Delta R^{2}$ & $.318^{* * *}$ & & $.312 * * *$ & \\
\hline \multicolumn{5}{|c|}{ Block 4: Different types of Facebook activities } \\
\hline Broadcasting & 0.200 & $3.013^{* *}$ & 0.171 & $2.493 * *$ \\
\hline Directed communication & 0.037 & 0.696 & -0.091 & -1.665 \\
\hline$\Delta R^{2}$ & $.035^{* *}$ & & $.015^{*}$ & \\
\hline \multicolumn{5}{|c|}{ Block 5: Facebook addiction } \\
\hline Facebook addiction & - & & 0.291 & $5.226^{* * *}$ \\
\hline$\Delta R^{2}$ & & & $.047 * * *$ & \\
\hline \multicolumn{5}{|l|}{ Block 5: Gender $\times$ Trait } \\
\hline Gender $\times$ Trait anxiety & 0.204 & $3.161^{* *}$ & -0.036 & -0.954 \\
\hline$\Delta R^{2}$ & $.032 * *$ & & .003 & \\
\hline Total $\Delta R^{2}$ & .442 & & .401 & \\
\hline
\end{tabular}

Note. $\beta$ : standardized regression coefficients.

${ }^{*} p<.05$. ${ }^{* *} p<.01 .{ }^{* * *} p<.001$.

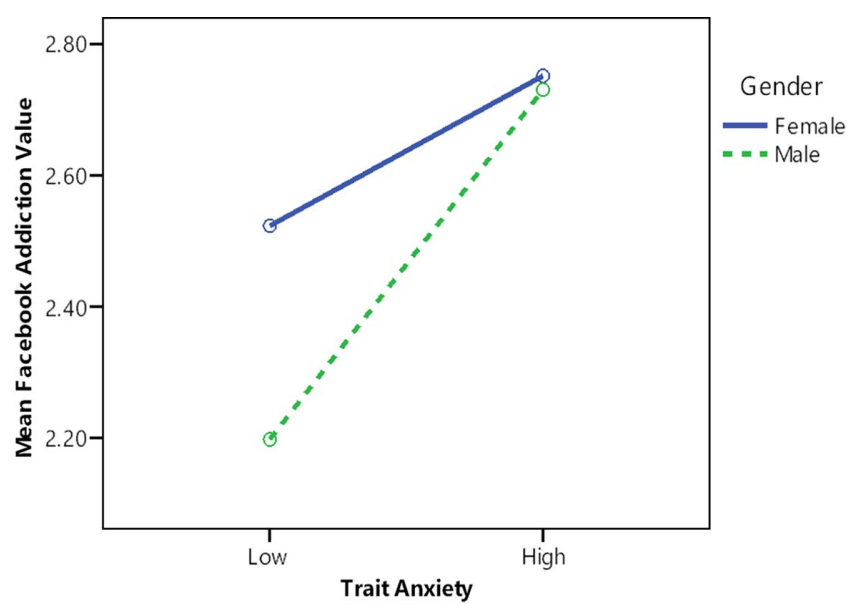

Figure 1. Predicting Facebook addiction by gender and trait anxiety

The more intensively people used Facebook, the more addicted they were to it $(\beta=0.573, p<.001,95 \%$ CI $[0.201,0.357])$ and the more anxious they felt when separated from Facebook $(\beta=0.567, p<.001,95 \%$ CI $[0.325$, $0.548]$ ), supporting both $H 5 a$ and $H 5 b$. Facebook use intensity was the strongest predictor and explained $31.8 \%$ of the variances in Facebook addiction $\left(\Delta R^{2}=.318\right.$, $p<.001)$ and $31.2 \%$ of the variances in state anxiety without Facebook $\left(\Delta R^{2}=.312, p<.001\right)$.
Regarding $R Q 2$, hierarchical regression analysis showed that SNS use for broadcasting such as status updating, sharing photos, or sharing videos increased both Facebook addiction $(\beta=0.200, p<.01,95 \%$ CI $[0.010,0.066])$ and Facebook state anxiety $(\beta=0.171, p<.01,95 \%$ CI $[0.012,0.093])$.

\section{DISCUSSION AND CONCLUSIONS}

Using a survey with 526 college students, this study tried to assess Facebook addiction and state anxiety without Facebook and examine the relationship between Facebook use, personalities, and Facebook addiction and anxiety. Although previous studies suggest that certain personality traits may be important in the acquisition and development of Facebook addiction, most of those studies focused on the Big-Five personalities (Hong et al., 2014; Marino et al., 2018a; Ong et al., 2011; Ross et al., 2009; Tang, Chen, Yang, Chung, \& Lee, 2016). Marino et al. (2018a) indicated that research efforts should be devoted to other types of personalities. One novel finding in this study is that we differentiated trait anxiety from state anxiety and identified trait anxiety as a strong personality factor for Facebook addiction and state anxiety without Facebook, echoing previous psychological research (Mehroof \& Griffiths, 2010). It may be because people with higher level of trait anxiety tend to use Facebook to escape from the stress in real life and are more likely to be addicted to this virtual 
world (Hong et al., 2014; Satici et al., 2014). Such results also show that people with higher level of trait anxiety are more likely to feel anxious when they are separated from SNSs. Given the lack of the attention to trait anxiety in addiction research, we suggest that trait anxiety deserves more attention in technology addiction research.

Another novel finding from this study is that we found trait anxiety interacts with gender in predicting Facebook addiction. When trait anxiety is low, women are more addicted to Facebook than men, consistent with the findings from previous research (Andreassen et al., 2013; Thompson \& Lougheed, 2012). However, when trait anxiety is high, such gender difference does not exist. This suggests that men are more resistant to Facebook addiction when their trait anxiety is low. For men with high trait anxiety, such resistance disappears. Marino et al. (2018b) suggested that future research should examine individual and contextual factors that may serve as a moderator. These findings suggest that the relationship between gender and Facebook addiction is complicated and trait anxiety can play a significant moderating role and thus deserves more examination.

Consistent with previous research using both self-report (Hong et al., 2014; Thompson \& Lougheed, 2012) and objective measures (Marino et al., 2018a, 2018b), the results in this study showed that those who use Facebook more intensively are more addicted to Facebook and report higher level of state anxiety without Facebook. In fact, previous studies argued that the frequency of use is part of the problematic Facebook use (Hormes et al., 2014; Marino et al., 2018a, 2018b). It is worth noting that this study adopted the Facebook use intensity scale, which not only measures Facebook use frequency, but also focuses more on the psychological and emotional attachment to Facebook (Ellison et al., 2007). This result suggests that those who spend more time on Facebook and psychologically rely on Facebook should be more aware of the potential mental health problem.

We categorized different types of SNS activities and examined their relationship with Facebook addiction. Consistent with Marino et al.'s (2017) findings, we found that updating status and sharing photos and videos strongly predicts Facebook addiction, and this relationship remains robust even after controlling for Facebook use intensity. However, in contrast with Marino et al.'s (2017) findings, wall activities such as "liking" or commenting are not related to Facebook addiction. This discrepancy may lay in the fact that Facebook activities were measured using self-report in this study, while Marino et al. (2017) used objective measures by downloading Facebook users' data, which are more objective and reliable. These findings reflect that different types of activities on SNSs may be associated with different psychological aspects of SNSs (Burke et al., 2011; Ryan et al., 2014, 2016).

However, this study has several limitations. First, we used single center data resources, who were university students, implying that the results cannot be generalized to other demographic groups. Second, the study had medium sample size $(N=526)$, which may influence the external validity of the study. However, meta-analysis on Facebook addiction showed only 15 out of the 52 published studies used a sample larger than 500 people (Marino et al., 2018b), suggesting most of the research on Facebook addiction still use a relatively small sample size. Third, the cross-sectional design precludes the ability to make conclusions of causality (Pantic, 2014). Thus, it is unclear whether intensive use of Facebook increases Facebook addiction or if Facebook addiction increases time spent on SNSs. Marino et al. (2018a, 2018b) found that this domain of research is still dominated by cross-sectional studies. Future research may adopt longitudinal or experimental design to test causalities. Fourth, as data from this study depended on subjects' self-report, the validity of the measurements about mental health variables may be influenced by the social desirability problem (Fisher, 1993).

In conclusion, this study explored the predictors of Facebook addiction and state anxiety, including trait anxiety, gender, Facebook intensity, and different types of Facebook activities. Our findings have several implications. First, we identified trait anxiety not only predicts Facebook addiction and state anxiety, but also moderates the relationship between gender and Facebook addiction. Facebook addiction, in turn, is positively related to state anxiety without Facebook. This may suggest that addiction to the virtual world such as Facebook may affect people's real life (O'Keeffe \& Clarke-Pearson, 2011) and psychological well-being, especially among those with highly anxious personality. From a clinical perspective, this would imply that psychiatrists and counseling psychologists should pay more attention to psychologically vulnerable groups, especially those with high trait anxiety, as they are at special risks of Facebook addiction and state anxiety. Second, although overall Facebook use may lead to Facebook addiction, people need to limit their time in certain types of behavior such as status updating and sharing user-generated content because such activities may increase their addictive symptoms and state anxiety when separated from Facebook. For the younger generation, parents and educators need to monitor not only the total time that they spend online, but also the specific online activities. Third, future studies may adopt physiological measurements to evaluate Facebook addiction and anxiety levels, or data mining techniques to obtain objective user behavior data on Facebook.

Funding sources: No funding has been received for this study.

Authors' contribution: Dr. WX was involved in literature review, questionnaire development, data collection, statistical analysis, results, and discussions. Dr. KK was involved in literature review, questionnaire development, and discussions.

Conflict of interest: There is no conflict of interest between the authors.

\section{REFERENCES}

American Psychiatric Association. (2013). Diagnostic and statistical manual of mental disorders (5th ed.). Arlington, VA: American Psychiatric Association. 
Andreassen, C. S., Griffiths, M. D., Gjertsen, S. R., Krossbakken, E., Kvam, S., \& Pallesen, S. (2013). The relationships between behavioral addictions and the five-factor model of personality. Journal of Behavioral Addictions, 2(2), 90-99. doi:10.1556/ JBA.2.2013.003

Andreassen, C. S., \& Pallesen, S. (2014). Social network site addiction - An overview. Current Pharmaceutical Design, 20(25), 4053-4061. doi:10.2174/13816128113199990616

Andreassen, C. S., Torsheim, T., Brunborg, G. S., \& Pallesen, S. (2012). Development of a Facebook Addiction Scale 1, 2. Psychological Reports, 110(2), 501-517. doi:10.2466/02.09. 18.PR0.110.2.501-517

Barker, V. (2009). Older adolescents' motivations for social network site use: The influence of gender, group identity, and collective self-esteem. CyberPsychology \& Behavior, 12(2), 209-213. doi:10.1089/cpb.2008.0228

Beyens, I., Frison, E., \& Eggermont, S. (2016). "I don't want to miss a thing": Adolescents' fear of missing out and its relationship to adolescents' social needs, Facebook use, and Facebook related stress. Computers in Human Behavior, 64, 1-8. doi:10.1016/j.chb.2016.05.083

Brailovskaia, J., \& Margraf, J. (2017). Facebook Addiction Disorder (FAD) among German students - A longitudinal approach. PLoS One, 12(12), e0189719. doi:10.1371/journal.pone.0189719

Burke, M., Kraut, R., \& Marlow, C. (2011, May). Social capital on Facebook: Differentiating uses and users. Paper presented at Proceedings of the SIGCHI conference on human factors in computing systems, ACM, New York, NY, pp. 571-580.

Burke, M., \& Kraut, R. E. (2016). The relationship between Facebook use and well-being depends on communication type and tie strength. Journal of Computer-Mediated Communication, 21(4), 265-281. doi:10.1111/jcc4.12162

Castillo, S. (2015). Facebook addiction activates same brain areas as drugs; How social media sites hook you in. Retrieved January 31, 2015, from http://www.medicaldaily.com/facebook-addictionactivates-same-brain-areas-drugs-how-social-media-sites-hookyou-320252

Chaffey, D. (2017). Global social media research summary 2017. Retrieved April 27, 2017, from https://www.smartinsights. com/social-media-marketing/social-media-strategy/new-globalsocial-media-research/

Dhaha, I. (2013). Predictors of Facebook addiction among youth: A structural equation modeling. Journal of Social Sciences, 2(4), 186-195.

Donner, N. C., \& Lowry, C. A. (2013). Sex differences in anxiety and emotional behavior. Pflügers Archiv - European Journal of Physiology, 465(5), 601-626. doi:10.1007/s00424-0131271-7

Dunteman, G. H. (1989). Principal components analysis. London, UK: Sage.

Elihu, K., Blumler, J., \& Gurevitch, M. (1974). Utilization of mass communication by the individual. In J. Blumler \& E. Katz (Eds.), The uses of mass communications: Current perspectives on gratifications research (pp. 19-31). Beverly Hills, CA: Sage.

Ellison, N. B., Steinfield, C., \& Lampe, C. (2007). The benefits of Facebook "friends": Social capital and college students' use of online social network sites. Journal of Computer-Mediated Communication, 12(4), 1143-1168. doi:10.1111/j.1083-6101. 2007.00367.x
Fisher, R. J. (1993). Social desirability bias and the validity of indirect questioning. Journal of Consumer Research, 20(2), 303-315.doi:10.1086/209351

Gaille, B. (2017). 43 remarkable Facebook addiction statistics. Retrieved May 29, 2017, from https://brandongaille.com/42remarkable-facebook-addiction-statistics/

Gidron, Y. (2013). Trait anxiety. In M. D. Gellman \& J. R. Turner (Eds.), Encyclopedia of behavioral medicine. New York, NY: Springer.

Greenwood, S., Perrin, A., \& Duggan, M. (2016). Social media update 2016. Retrieved November 11, 2016, from http://www.pewinternet.org/2016/11/11/social-media-update2016/

Griffiths, M. D. (2010). Gaming in social networking sites: A growing concern? World Online Gambling Law Report, 9(5), $12-13$.

Hawi, N. S., \& Samaha, M. (2017). Relationships among smartphone addiction, anxiety, and family relations. Behaviour \& Information Technology, 36(10), 1046-1052. doi:10.1080/ 0144929X.2017.1336254

Hishinuma, E. S., Miyamoto, R. H., Nishimura, S. T., \& Nahulu, L. B. (2000). Differences in State-Trait Anxiety Inventory scores for ethnically diverse adolescents in Hawaii. Cultural Diversity and Ethnic Minority Psychology, 6(1), 73-83. doi:10.1037/1099-9809.6.1.73

Hormes, J. M., Kearns, B., \& Timko, C. A. (2014). Craving Facebook? Behavioral addiction to online social networking and its association with emotion regulation deficits. Addiction, 109(12), 2079-2088. doi:10.1111/add.12713

Hong, F.-Y., Huang, D.-H., Lin, H.-Y., \& Chiu, S.-L. (2014). Analysis of the psychological traits, Facebook usage, and Facebook addiction model of Taiwanese university students. Telematics and Informatics, 31(4), 597-606. doi:10.1016/j. tele.2014.01.001

Ikeda, K., \& Nakamura, K. (2014). Association between mobile phone use and depressed mood in Japanese adolescents: A cross-sectional study. Environmental Health and Preventive Medicine, 19(3), 187-193. doi:10.1007/s12199-013-0373-3

Kandell, J. (1998). Internet addiction on campus: The vulnerability of college students. CyberPsychology \& Behavior, 1(1), 11-17. doi:10.1089/cpb.1998.1.11

Karaiskos, D., Tzavellas, E., Balta, G., \& Paparrigopoulos, T. (2010). P02-232 - Social network addiction: A new clinical disorder? European Psychiatry, 25, 855. doi:10.1016/S09249338(10)70846-4

Koc, M., \& Gulyagci, S. (2013). Facebook addiction among Turkish college students: The role of psychological health, demographic, and usage characteristics. Cyberpsychology, Behavior, and Social Networking, 16(4), 279-284. doi:10.1089/ cyber.2012.0249

Kushner, M. G., Krueger, R., Frye, B., \& Peterson, J. (2008). Epidemiological perspectives on co-occurring anxiety disorder and substance use disorder. In S. Stewart \& P. Conrod (Eds.), Anxiety and substance use disorders (pp. 3-17). Boston, MA: Springer.

Kuss, D. J., \& Griffiths, M. D. (2011). Online social networking and addiction - A review of the psychological literature. International Journal of Environmental Research and Public Health, 8(9), 3528-3552. doi:10.3390/ijerph8093528

Kuss, D. J., Griffiths, M. D., Karila, L., \& Billieux, J. (2014). Internet addiction: A systematic review of epidemiological 
research for the last decade. Current Pharmaceutical Design, 20(25), 4026-4052. doi:10.2174/13816128113199990617

Lai, H., Cleary, M., Sitharthan, T., \& Hunt, G. E. (2015). Prevalence of comorbid substance use, anxiety and mood disorders in epidemiological surveys, 1990-2014: A systematic review and meta-analysis. Drug and Alcohol Dependence, 154, 1-13. doi:10.1016/j.drugalcdep.2015.05.031

Lazarus, R. S. (1991). Emotion and adaptation. London, UK: Oxford University Press.

Lewinsohn, P. M., Gotlib, I. H., Lewinsohn, M., Seeley, J. R., \& Allen, N. B. (1998). Gender differences in anxiety disorders and anxiety symptoms in adolescents. Journal of Abnormal Psychology, 107(1), 109-117. doi:10.1037/0021-843X.107.1.109

Li, H., \& Lopez, V. (2005). Do trait anxiety and age predict state anxiety of school-age children? Journal of Clinical Nursing, 14(9), 1083-1089. doi:10.1111/j.1365-2702.2005.01223.x

Litt, M. D., Cooney, N. L., \& Morse, P. (2000). Reactivity to alcohol-related stimuli in the laboratory and in the field: Predictors of craving in treated alcoholics. Addiction, 95(6), 889-900. doi:10.1046/j.1360-0443.2000.9568896.x

Marino, C., Finos, L., Vieno, A., Lenzi, M., \& Spada, M. M. (2017). Objective Facebook behaviour: Differences between problematic and non-problematic users. Computers in Human Behavior, 73, 541-546. doi:10.1016/j.chb.2017.04.015

Marino, C., Gini, G., Vieno, A., \& Spada, M. M. (2018a). A comprehensive meta-analysis on problematic Facebook use. Computers in Human Behavior, 83, 262-277. doi:10.1016/j. chb.2018.02.009

Marino, C., Gini, G., Vieno, A., \& Spada, M. M. (2018b). The associations between problematic Facebook use, psychological distress and well-being among adolescents and young adults: A systematic review and meta-analysis. Journal of Affective Disorders, 226, 274-281. doi:10.1016/j.jad.2017.10.007

Marteau, T., \& Bekker, H. (1992). The development of a six-item short-form of the state scale of the Spielberger State-Trait Anxiety Inventory (STAI). British Journal of Clinical Psychology, 31(3), 301-306. doi:10.1111/j.2044-8260.1992.tb00997.x

McCrary, J. (2016). How social media addictions strain relationships with college students. Retrieved November 28, 2016, from http://progressions.prssa.org/index.php/2016/11/28/how-socialmedia-addictions-strain-relationships-with-college-students/

McLean, C. P., \& Anderson, E. R. (2009). Brave men and timid women? A review of the gender differences in fear and anxiety. Clinical Psychology Review, 29(6), 496-505. doi:10.1016/j. cpr.2009.05.003

Mehroof, M., \& Griffiths, M. D. (2010). Online gaming addiction: The role of sensation seeking, self-control, neuroticism, aggression, state anxiety, and trait anxiety. Cyberpsychology, Behavior, and Social Networking, 13(3), 313-316. doi:10. 1089/cyber.2009.0229

O'Keeffe, G. S., \& Clarke-Pearson, K. (2011). The impact of social media on children, adolescents, and families. Pediatrics, 127(4), 800-804. doi:10.1542/peds.2011-0054

Ong, E. Y., Ang, R. P., Ho, J. C., Lim, J. C., Goh, D. H., Lee, C. S., \& Chua, A. Y. (2011). Narcissism, extraversion and adolescents' self-presentation on Facebook. Personality and Individual Differences, 50(2), 180-185. doi:10.1016/j.paid.2010. 09.022

Pantic, I. (2014). Online social networking and mental health. Cyberpsychology, Behavior, and Social Networking, 17(10), 652-657. doi:10.1089/cyber.2014.0070
Park, S., \& Choi, J. W. (2015). Subjective symptoms of Visual Display Terminal Syndrome and state anxiety in adolescent smartphone users. International Journal of Contents, 11(4), 31-37. doi:10.5392/IJoC.2015.11.4.031

Prizant-Passal, S., Shechner, T., \& Aderka, I. M. (2016). Social anxiety and Internet use - A meta-analysis: What do we know? What are we missing? Computers in Human Behavior, 62, 221-229. doi:10.1016/j.chb.2016.04.003

Przepiorka, A., \& Blachnio, A. (2016). Time perspective in Internet and Facebook addiction. Computers in Human Behavior, 60, 13-18. doi:10.1016/j.chb.2016.02.045

Ross, C., Orr, E. S., Sisic, M., Arseneault, J. M., Simmering, M. G., \& Orr, R. R. (2009). Personality and motivations associated with Facebook use. Computers in Human Behavior, 25(2), 578-586. doi:10.1016/j.chb.2008.12.024

Ryan, T., Chester, A., Reece, J., \& Xenos, S. (2014). The uses and abuses of Facebook: A review of Facebook addiction. Journal of Behavioral Addictions, 3(3), 133-148. doi:10.1556/JBA.3. 2014.016

Ryan, T., Reece, J., Chester, A., \& Xenos, S. (2016). Who gets hooked on Facebook? An exploratory typology of problematic Facebook users. Cyberpsychology: Journal of Psychosocial Research on Cyberspace, 10(3), Article 4. doi:10.5817/ CP2016-3-4

Seligman, M. E. P., Walker, E. F., \& Rosenhan, D. L. (2001). Abnormal psychology. New York, NY: W. W. Norton \& Company, Inc.

Simoncic, T. E., Kuhlman, K. R., Vargas, I., Houchins, S., \& LopezDuran, N. L. (2014). Facebook use and depressive symptomatology: Investigating the role of neuroticism and extraversion in youth. Computers in Human Behavior, 40, 1-5. doi:10.1016/j. chb.2014.07.039

Smahel, D., Blinka, L., \& Ledabyl, O. (2008). Playing MMORPGs: Connections between addiction and identifying with a character. CyberPsychology \& Behavior, 11(6), 715-718. doi: $10.1089 / \mathrm{cpb} .2007 .0210$

Smith, A., \& Anderson, M. (2018). Social media use in 2018. Retrieved March 1, 2018, from http://www.pewinternet.org/ 2018/03/01/social-media-use-in-2018/

Spielberger, C. D. (1966). Theory and research on anxiety. In C. D. Spielberger (Ed.), Anxiety and behavior (pp. 3-20). New York, NY: Academic Press.

Spielberger, C. D. (1972). Anxiety as an emotional state. In C. D. Spielberger (Ed.), Anxiety-Current trends and theory (pp. 319). New York, NY: Academic Press.

Spielberger, C. D. (2010). State-Trait Anxiety Inventory. Hoboken, NJ: John Wiley \& Sons, Inc.

Satici, B., Saricali, M., Statici, S., \& Capan, B. (2014). Social competence and psychological vulnerability as predictors of Facebook addiction. Studia Psychologica, 56(4), 301-308. doi:10.21909/sp.2014.04.738

Tang, J. H., Chen, M. C., Yang, C. Y., Chung, T. Y., \& Lee, Y. A. (2016). Personality traits, interpersonal relationships, online social support, and Facebook addiction. Telematics and Informatics, 33(1), 102-108. doi:10.1016/j.tele.2015.06.003

Thompson, S. H., \& Lougheed, E. (2012). Frazzled by Facebook? An exploratory study of gender differences in social network communication among undergraduate men and women. College Student Journal, 46(1), 88-99.

Tluczek, A., Henriques, J. B., \& Brown, R. L. (2009). Support for the reliability and validity of a six-item State Anxiety Scale 
derived from the State-Trait Anxiety Inventory. Journal of Nursing Measurement, 17(1), 19-28. doi:10.1891/1061-3749. 17.1.19

Turel, O., He, Q., Xue, G., Xiao, L., \& Bechara, A. (2014). Examination of neural systems sub-serving Facebook "addiction”. Psychological Reports, 115(3), 675-695. doi:10.2466/ 18.PR0.115c31z8

West, R., \& Brown, J. (2013). Theory of addiction. Chichester, UK: John Wiley \& Sons, Inc.

Xie, W., \& Kang, C. (2015). See you, see me: Teenagers' selfdisclosure and regret of posting on social network site.
Computers in Human Behavior, 52, 398-407. doi:10.1016/j. chb.2015.05.059

Xie, W., \& Newhagen, J. E. (2014). The effects of communication interface proximity on user anxiety for crime alerts received on desktop, laptop, and hand-held devices. Communication Research, 41(3), 375-403. doi:10.1177/ 0093650212448670

Zhong, B. (2013). From smartphones to iPad: Power users' disposition toward mobile media devices. Computers in Human Behavior, 29(4), 1742-1748. doi:10.1016/j.chb.2013. 02.016 